\title{
Puerperal Morbidities After Delivery in a Tertiary Care Referral Hospital of Nepal
}

\author{
Rosy Malla and Reeta Manandhar
}

Nepalese Army Institute of Health Sciences, Kathmandu, Nepal.

ABSTRACT
Introduction: : In a developing country like Nepal maternal morbidity in the post partum
period is a major healthcare concern. This study aims to analyze the maternal morbidities in
women following delivery at Shree Birendra Hospital.
Methods: This is a prospective, observational, hospital based study, carried out at Shree
Birendra Hospital from $13^{\text {th }}$ August 2012 to $13^{\text {th }}$ Feb 2016 . Women who underwent delivery
in Shree Birendra Hospital with subsequent morbidities within the study period were
included in this study. The variables considered in this study were pattern of postpartum
morbidities, age, parity, mode of delivery and average duration of hospital stay.
Results: During the study period, a total number of 3407 deliveries were conducted in Shree
Birendra Army Hospital. Out of these, 54 patients (1.58\%) had postpartum morbidities.
Puerperal sepsis was the most frequent diagnosis seen in 18 patients (33.3\%), followed by
surgical wound infection in 14 (25.9\%) and secondary postpartum hemorrhage (PPH) in 10
(18.5\%).
Conclusion: Puerperal sepsis remains the most common cause of postpartum morbidity.
Keywords: postpartum morbidity; postpartum hemorrhage; puerperal sepsis.

\section{INTRODUCTION}

The Puerperium is a special but crucial time for both the mother and the infant as this is the period when women recover from labour and revert back to physically to the non-pregnant state. The WHO defines the postpartum period, or puerperium, as beginning one hour after the delivery of the placenta and continuing till six weeks after the birth of the infant. ${ }^{1}$

The challenge for a developing country like Nepal is making motherhood safe. This can be achieved only by proper education, good communication and bringing about social change. Skilled birth attendants and encouraging midwifery practices will significantly reduce morbidities as well as mortalities.

Information on the extent of postpartum morbidity in developing countries is limited especially in the context of Nepal. This study was thus carried out in Shree Birendra Hospital, which is a tertiary level welfare hospital for army, retired army personnel and their families. Obstetric services in the hospital

Correspondence: Rosy Malla, Department of Obstetrics and Gynaecology, Nepalese Army Institute of Health Sciences, Email: rosymalla@hotmail.com 
were, however recently started from $13^{\text {th }}$ August 2012. Hence this study has been conducted to find out the burden and pattern of morbidities in postpartum period.

\section{METHODS}

This is a prospective, observational, hospital based study, carried out at Shree Birendra Hospital from 13 $3^{\text {th }}$ August 2012 to $13^{\text {th }}$ Feb 2016. A daily record of all obstetric cases admitted in the hospital was made from admission records. All postpartum morbidities among cases delivered at SBH was recorded to estimate the incidence, the cause, the average duration of hospital stay as well to analyze morbidities in relation to age, parity, gestational age and mode of delivery.

For the purpose of this study, the WHO definition of the postpartum period (from delivery until 6 weeks after delivery) was used. Women who underwent deliveries in Shree Birendra Hospital with subsequent morbidities within the study period were included in this study. Patients delivered in other hospitals or other settings and admitted for post partum complications were excluded. Similarly, post partum morbidities due to domestic or road traffic accidents were excluded. Patients admitted in the post partum period for neonatal complications were similarly excluded.

The study focused on the incidence, types of morbidities, average duration of hospital stay and analyzed postpartum morbidities in relation to age, parity and mode of delivery. Data was collected on a structured pro-forma covering the relevant information required for the study. Data was then compiled on a computer on a SPSS (Statistical package for social science) for windows version 16.0 and analyzed.

\section{RESULTS}

During the study period, a total number of 3407 deliveries were conducted in Shree Birendra Army hospital. Out of these, 54 patients had postpartum morbidities. Consequently the incidence of postpartum morbidities in this study period was calculated to be $1.58 \%$.

During this period 2361(69.3\%) had normal vaginal deliveries, while 1046(30.7\%) underwent Cesarean section. Among 2361 patients undergoing vaginal deliveries, 38 (1.61\%) had postpartum morbidities, whereas out of 1046 Cesarean section deliveries, 16 (1.53\%) patients were admitted with postpartum morbidities. The incidence of postpartum morbidities in this study, in vaginal deliveries was $1.61 \%$ and in Cesarean section it was $1.53 \%$.

The distribution of age, parity and period of gestation in the patients with postpartum morbidities were similar in both the groups. (Table 1)

Puerperal sepsis was the most frequent diagnosis seen in 18 patients $(33.3 \%)$, followed by surgical wound infection in 14 (25.9\%), secondary PPH 10 (18.5\%). UTI, hypertensive

Table 1: Distribution of respondents according to socio-demographic Characteristics $(\mathrm{n}=121)$.

\begin{tabular}{|l|l|l|}
\hline \multicolumn{2}{|c|}{$\begin{array}{l}\text { Cesarean } \\
\text { section }(\mathrm{n}=16)\end{array}$} & $\begin{array}{l}\text { Normal } \\
\text { deliveries } \\
(\mathrm{n}=38)\end{array}$ \\
\hline Age (mean) & $26.7 \mathrm{yrs}$ & $25.6 \mathrm{yrs}$ \\
\hline $\begin{array}{l}\text { Parity } \\
\text { (median) }\end{array}$ & 1 & 1 \\
\hline $\begin{array}{l}\text { Period of } \\
\text { Gestation } \\
\text { (median) }\end{array}$ & $39-40 \mathrm{wks}$ & $39-40 \mathrm{wks}$ \\
\hline
\end{tabular}




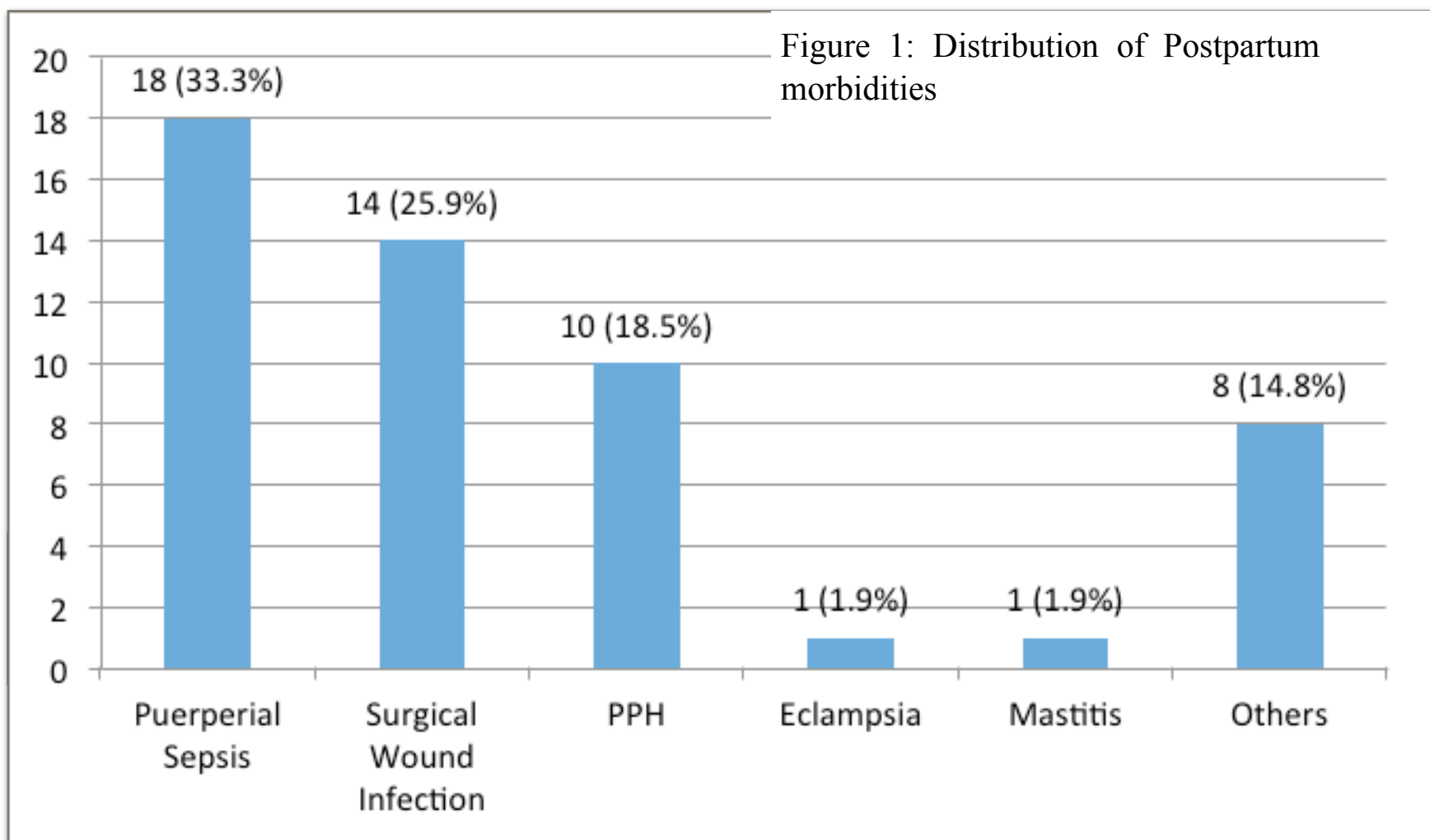

Table 2: postpartum morbidities in C-section and vaginal delivery group

\begin{tabular}{|l|c|c|}
\hline & $\begin{array}{c}\text { Cesarean } \\
\text { Section } \\
\mathbf{n = 1 6}\end{array}$ & $\begin{array}{c}\text { Vaginal } \\
\text { delivery } \\
\mathbf{n}=38\end{array}$ \\
\hline Puerperal Sepsis & 4 & 14 \\
\hline $\begin{array}{l}\text { Surgical Wound } \\
\text { infection }\end{array}$ & 10 & 2 \\
\hline $\begin{array}{l}\text { Hypertensive disorders } \\
\text { of pregnancy }\end{array}$ & 1 & 0 \\
\hline PPH & 0 & 10 \\
\hline Urinary Tract Infection & 1 & 0 \\
\hline Mastitis & 0 & 2 \\
\hline Others & 0 & 8 \\
\hline
\end{tabular}

disorders of pregnancy, infective hepatitis and postpartum cadiomyopathies were other diagnosis. (Figure 1).

Out of 54 patients who had post partum complications, 38 patients had undergone vaginal delivery and 16 women had undergone caesarean section. Puerperal sepsis was the leading cause of morbidity in vaginal delivery group while surgical wound infection in cesarean group. (Table 2).

The average duration of hospital stay in vaginal delivery morbidities was 5.6 days whereas in $\mathrm{C}$-section it was 8.7 days.

\section{DISCUSSION}

The national essential maternal and neonatal health care service package for Nepal recommends three postnatal visits for all women, whether delivered at home or in other facilities. ${ }^{2}$ The aim of these visits were to detect life threatening complications like PPH, infection, injuries, severe preeclampsia and newborn complications to ensure proper treatment to reduce maternal and neonatal mortality and morbidity.

In this study the incidence of postpartum morbidity was $1.58 \%$. Similar incidence of 1.94\% was reported from Paropakar Maternity and Women's Hospital, Thapathali, Nepal in 2007 over a three months period. ${ }^{3}$ Similar study done in India in 1999 - 2002 reported 
$2.2 \%$ of all obstetric admissions (9080 cases) were due to postpartum complications. ${ }^{4}$ The finding is similar with a study of Lusaka, Zambia where the incidence was $1.7 \%{ }^{5}$

In this study, Puerperal sepsis was the most frequent diagnosis comprising $33.3 \%$, followed by surgical wound infection (25.9\%) and secondary PPH (18.5\%). A study done in Lusaka, Zambia in 2000, also found that puerperial sepsis was the most common complications $(34.8 \%)$. Others were malaria $(14.5 \%)$ and pregnancy induced hypertension $(10.9 \%)$. In a review of patients having was puerperial sepsis after having delivered in Ife state hospital, Nigeria, in the year 1980-1995, 146(1.7\%) among 8428 total deliveries had puerperial sepsis. ${ }^{6}$ The incidence was higher among unbooked cases $(71.2 \%)$. Hence their study encouraged antenatal care and supervised hospital delivery in order to prevent or reduce the seriousness of postpartum morbidity. In our study, surgical wound infection compromised $25.9 \%$ of morbidities indicating a need for more careful infection prevention practices.

In this study, the secondary PPH was found in $18.5 \%$, of which $37.5 \%$ women required surgical uterine evacuation and rest of them were treated conservatively. During the course of treatment $18.5 \%$ women required blood transfusion. A study done in Patan hospital, Nepal, in Aug 2005-Aug 2006 found the incidence of secondary $\mathrm{PPH}$ to be $0.42 \% .^{7}$ Majority cause for secondary PPH was retained POC. In this study, the postpartum UTI was found in $1.95 \%$ and similarly hypertensive disorders were detected in $1.9 \%$.

During the study period, out of 54 patients who had postpartum morbidities 38 patients (70.4\%) had vaginal deliveries and 16 (29.6\%) required caesarean section which is not similar MJSBH Vol 15 Issue 2 July-Dec 2016 to the Cohort study conducted in Canada between 1995 and 2001 which showed that caesarean section delivery was associated with significantly increased risk of postpartum morbidities compared to spontaneous vaginal delivery. ${ }^{8}$ C-section was associated with increased risk for uterine infection, surgical wound infection, cardiopulmonary and thrombotic conditions. In a study done in Patan hospital in the year 2006, considering the mode of delivery among all secondary PPH cases, $77 \%$ had spontaneous vaginal delivery, $12 \%$ cesarean delivery and $7 \%$ had vacuum delivery and breech and twin constituted $2 \%$ in each. ${ }^{5}$ This study also showed increased number of patients had vaginal delivery with PPH.

In this study, there is a similar distribution in age, parity and period of gestation in both Csection and vaginal deliveries with mean age 25.9 years and having median parity of one. A retrospective study conducted at Nepal Medical College Teaching Hospital, Jorpati in 2004 reported that, among 1619 postpartum admissions $57.9 \%$ were between 20-25 years and $17 \%$ were teenagers. ${ }^{9}$ The study also showed $88(5.4 \%)$ were primiparous among total postpartum admissions.

In this study the average duration of hospital stay with morbidities in vaginal delivery was 5.6 days as compared to 8.7 days in cesarean section. A population based cohort study done in Canada between 1995 and 2001 showed that, length of hospital stay averaged 3.5 days for C-Section, 2.9 days for forceps and 2.7 days for both vacuum and spontaneous vaginal delivery. ${ }^{8}$

\section{CONCLUSION}

It The most frequent morbidity encountered in the women delivered at Shree Birendra Hospital was puerperial sepsis (33.3\%), 
followed by surgical wound infection (25.9\%), secondary PPH (18.5\%), UTI, hypertensive disorders of pregnancy, infective hepatitis and postpartum cardiomyopathies.

\section{REFERENCES}

1. World Health Organization: Postpartum care of mother and newborn: a practical guide. WHO/RHT/MSM/98.3. Geneva: WHO; 1998.

2. Government of Nepal, Ministry of Health and Population, Family Health Division. Introduction. In: National Medical standard for reproductive health: maternal and neonatal care. 2007; vol iii: vi-vii.

3. Raut BB. Readmissions for morbidities among postpartum women delivered at Paropakar maternity and women's hospital [MD Thesis]. National Academy of Medical Sciences; 2009.

4. Shankuntala C, Verma S, Ritambara B. Quality of postpartum care. J Obstet Gynecol India 2006; 56: 142-146.

5. Vallely L, Ahmed Y, Murray SF. Postpartum maternal morbidity requiring hospital admission in Lusaka, Zambia - a descriptive study. BMC Pregnancy and Childbirth 2005, 5: 1 DOI: https:// doi.org/ 10.1186/1471-2393-5-1

6. Dare FO, Bako AU, Ezechi OC. Puerperal Sepsis: a preventable post partum complication. Tropical Doct. 1998; 28(2): 92-9 5. DOI: https://doi org/ 10.1177/004947559802800212

7. Sharma P, Regmi M. Secondary PPH: A retrospective descriptive study. Journal of Society of Surgeons of Nepal 2007; 10 (3): 7-10

8. Liu S, et al. Risk of Maternal post partum readmission associated with mode of delivery. Obstetrics and Gynaecology (New York) 2005; 105: 836-842. DOI: https:// d o i.org/ $10.1097 / 01$. A O G . 0000154153.31193.2c

9. Tuladhar H, Dali SM, Pradhananga V. Complications of home delivery: a retrospective analysis. JNMA 2005; 44(159): 87-91. 